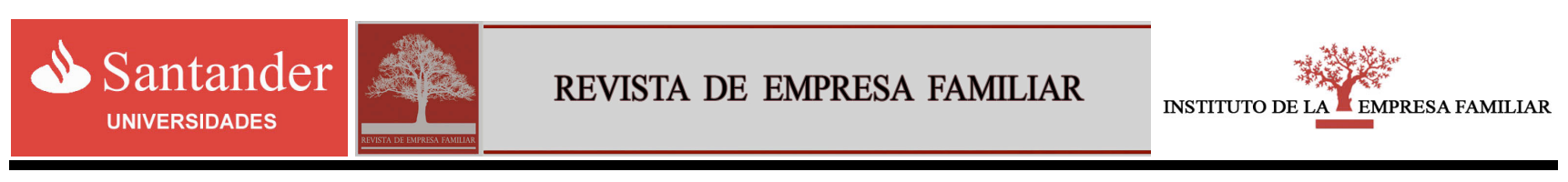

www.revistadeempresafamiliar.uma.es

\title{
El pago de las legítimas en dinero: un instrumento para planificar la sucesión en la Empresa Familiar
}

\section{Payment in money of forced shares in inheritance: an instrument for the planning of succession in Family Businesses}

\author{
Carlos M. Díez Soto ${ }^{\mathrm{a},}$
}

${ }^{a}$ Departamento de Ciencias Jurídicas. Universidad Politécnica de Cartagena, 30201 (Spain)

\begin{tabular}{l} 
D A T O S A R T Í C U L O \\
\hline Historial: \\
Recibido 18-06-2010 \\
Aceptado 13-12-2010 \\
Palabras clave: \\
Empresa familiar \\
Sucesión hereditaria \\
Pago de legítimas en dinero \\
Planificación sucesoria \\
Códigos JEL: \\
K36
\end{tabular}

A R T I C LE IN F O

\section{Article history:}

Received 18 June 2010

Accepted 13 December 2010

Keywords:

Family business

Hereditary succession

Payment of forced shares in money

Planning of succession

JEL codes:

K36

\begin{abstract}
R E S U M E N
En el sistema del Código Civil español, el testador está obligado a dejar una parte sustancial de su patrimonio a ciertos miembros de su familia (legitimarios), que además tienen derecho a recibir su cuota en bienes hereditarios. Este régimen puede generar importantes dificultades de cara a mantener la unidad y la continuidad de la empresa tras la muerte de su titular. No obstante, la ley prevé diferentes mecanismos que pueden ser utilizados para planificar de un modo eficiente la sucesión, evitando así la división de la empresa o la necesidad de proceder a su venta. Uno de los más importantes es la posibilidad de disponer, en ciertos casos y con determinados requisitos, que algunos de los legitimarios habrán de recibir su cuota en metálico o en bienes no pertenecientes a la herencia.
\end{abstract}

\footnotetext{
A B S T R A C T

Under the Spanish Civil Code, the testator is obliged to preserve a substantial part of his estate for the benefit of some members of his family, who are moreover entitled to receive their forced share in assets belonging to the inheritance. This regulation may generate important difficulties in order to keep the unity and continuity of the business after the owner's death. However, the law provides different mechanisms that may be used for an efficient planning of the succession, thus avoiding the division of the business or the necessity to sell it. One of the most important of these mechanisms is the possibility to stipulate, in certain cases and subject to specific requirements, that some of the forced heirs shall receive their share in money or assets which do not belong to the testator's estate.
}

\footnotetext{
Autor de contacto. Tel.: +34968325794

Correoselectrónicos: carlos.diez@upct.es
} 


\section{La planificación de la sucesión hereditaria en la empresa familiar conforme al Código Civil español: los límites a la libertad testamentaria del causante}

La necesidad de facilitar a las empresas familiares instrumentos para atender a los problemas que típicamente se plantean en su seno, con objeto de garantizar su consolidación y subsistencia, encuentra una de sus principales manifestaciones en el ámbito de la planificación del cambio generacional, que constituye un momento crítico en el devenir de este tipo de empresas.

Se suele decir que en el sistema del Código Civil español (en adelante, CC) la voluntad testamentaria del causante es "ley de la sucesión"; lo cierto, sin embargo, es que el testador está sometido a límites muy estrictos a la hora de ordenar su sucesión. En efecto, el CC de 1889, siguiendo los planteamientos liberalizadores de la Desamortización, optó por suprimir o restringir al máximo todos aquellos instrumentos jurídicos que históricamente habían servido a la finalidad de mantener indivisa la propiedad y vincularla a las familias de forma permanente (restricciones a los mayorazgos, sustituciones fideicomisarias y prohibiciones de disponer, prohibición de los pactos sucesorios, de los testamentos mancomunados y de la delegación de la facultad de testar, amplitud de las legítimas, etc.). En este sentido, la experiencia de los territorios sometidos al CC es muy distinta de la que tradicionalmente se ha seguido en los territorios forales (Navarra, Aragón, Baleares, Cataluña, Galicia y territorios forales vascos), donde existe una amplia libertad para el uso de diversos instrumentos (capitulaciones matrimoniales, pactos sucesorios, testamentos mancomunados, sociedades conyugales o familiares, pactos sobre convivencia familiar, etc.) orientados a favorecer el mantenimiento de la unidad de las explotaciones familiares especialmente de carácter agrario-, poniéndolas al servicio de las necesidades familiares.

En buena medida, y pese a los esfuerzos que se vienen realizando para actualizar las normas del Código, tales planteamientos siguen hoy vigentes, lo que determina que nuestro ordenamiento no siempre ofrezca la flexibilidad necesaria para atender a las necesidades de las empresas familiares. Una de las principales dificultades que el $\mathrm{CC}$ plantea de cara a garantizar la continuidad de estas empresas es sin duda la que deriva del sistema legitimario aplicable en el ámbito de la sucesión hereditaria.

\section{El sistema legitimario del Código Civil}

En efecto, el testador del CC está vinculado por las normas sobre "sucesión forzosa $\mathrm{o}$ legitimaria", en virtud de las cuales determinadas personas -descendientes, ascendientes y cónyuge no separado legalmente o de hecho al morir el causante- tienen derecho a percibir una parte del patrimonio del causante (una vez descontadas las deudas pendientes, pero con adición del valor de las donaciones realizadas en vida), llamada "legítima". El respeto a los derechos de los legitimarios o herederos forzosos es el principal límite a la facultad del causante de disponer libremente de sus bienes, en vida o para después de su muerte, si bien cuenta con un margen de libertad para determinar el modo de satisfacer las legítimas (por vía de legado, de institución de heredero o de donaciones realizadas en vida).

En el CC, y a diferencia de lo que sucede en los Derechos forales, las legítimas son especialmente amplias, y sólo cabe privar de ellas a los interesados cuando concurra alguna de las causas de desheredación o indignidad para suceder previstas por la Ley (arts. 848 y ss. $\mathrm{CC})$.

La amplitud de las legítimas es especialmente notable cuando el causante fallece dejando cónyuge e hijos, ya que en tal caso la legítima de los hijos y descendientes es de dos tercios del haber hereditario, de los que uno (legítima estricta) ha de ser repartido por partes iguales, mientras que el otro (mejora) puede ser distribuido libremente por el causante entre sus hijos y descendientes. La legítima del viudo, en tal caso, consistirá en el usufructo del tercio de mejora, mientras que el tercio restante es de libre disposición para el causante.

Por otra parte, los herederos forzosos tienen derecho a que su legítima les sea pagada 
precisamente con bienes hereditarios (legítima como "pars bonorum"); si los bienes asignados no pertenecen a la herencia (por ejemplo, mediante un legado de cosa ajena), se concede al legitimario la opción entre lo atribuido por el causante y su derecho de legítima (arg. ex art. $820.3^{\circ}$ ). Además, los herederos forzosos tienen derecho, como regla, a recibir su porción legitimaria libre de cualquier tipo de carga, gravamen, condición, sustitución o restricción impuestas en el testamento (art. 813,2).

En tanto la legítima no sea satisfecha, todos los bienes hereditarios están legalmente afectos en garantía de su pago, siendo dicho gravamen oponible incluso frente a terceros adquirentes de inmuebles a través de la mención registral de derechos legitimarios (art. 15 Ley Hipotecaria en adelante, LH-). Además, la naturaleza del derecho de los legitimarios determina que sea necesario su consentimiento para enajenar los bienes integrados en la herencia indivisa $\mathrm{y}$, según algunos, incluso para realizar la partición.

Tales circunstancias pueden generar importantes dificultades para ordenar la sucesión en la empresa familiar, ya que el margen de maniobra del causante se verá sensiblemente limitado a la hora de mantener la unidad de la explotación y atribuir su titularidad a las personas más cualificadas, especialmente cuando haya un único hijo (ya que en tal caso no hay mejora) o cuando no existan en la herencia otros bienes ajenos a la empresa dotados de un valor relevante y que puedan destinarse a satisfacer la porción de los restantes legitimarios.

No obstante, el CC pone a disposición del empresario diferentes mecanismos que tienden a compatibilizar el respeto a las legítimas con la mayor libertad del causante a la hora de planificar su sucesión, facilitando, por ejemplo, el pago de las legítimas en metálico, aun cuando éste no exista en la herencia o sea insuficiente, o mediante la entrega de otros bienes, lo que, eventualmente, permitirá evitar la división de la empresa, la pérdida del control sobre la misma, o la venta de bienes afectos a la explotación.

\section{Legado de finca "que no admita cómoda división" y mejora en cosa determinada}

El CC contiene desde su origen determinadas normas que, excepcionalmente, y con objeto de evitar situaciones inconvenientes 0 antieconómicas, permite mantener la eficacia de determinadas disposiciones testamentarias aunque las mismas puedan afectar al derecho de los legitimarios a recibir bienes hereditarios en pago de sus legítimas. Aunque no son normas específicamente pensadas para las empresas familiares, su aplicación puede contribuir a mantener la unidad de la explotación, compensando a los legitimarios afectados mediante el pago, por parte de los adjudicatarios de la misma, de una cantidad en metálico, aun cuando éste no exista en la herencia o sea insuficiente.

Así, el art. 821 permite mantener la eficacia de un legado que recaiga sobre una finca "que no admita cómoda división”, aun cuando dicho legado sea inoficioso por perjudicar a las legítimas, siempre que la reducción procedente no alcance la mitad del valor de la finca, si bien en tal caso el legatario, que puede ser un tercero extraño a la familia, habrá de abonar a los legitimarios la parte correspondiente en dinero. No parece que plantee dudas la posibilidad de aplicar por analogía esta norma cuando el legado se refiera a una explotación familiar.

Por su parte, el art. 829 permite mantener la eficacia de la mejora realizada en cosa determinada (por vía de legado o donación realizada por el causante a favor de uno de sus hijos o descendientes), aun cuando su valor exceda del tercio de mejora y de la parte de legítima estricta correspondiente al mejorado, si bien éste deberá abonar la diferencia en metálico a los demás interesados. En este caso no se prevé ningún aplazamiento para el pago en metálico de las legítimas, por lo que éste habrá de hacerse al contado y en el mismo momento de hacerse la partición, lo que puede generar problemas de liquidez para el adjudicatario de la empresa. En caso de incumplimiento de la obligación de pagar la diferencia en metálico, los demás legitimarios tendrán derecho, en cuanto acreedores, a exigir el cumplimiento forzoso, si bien se entiende 
que, a tal efecto, no podrán hacer valer ninguna afección real sobre el bien adjudicado en concepto de mejora.

\section{El pago de las legítimas en metálico conforme a los artículos 841-847 CC}

Conforme a los arts. 841-847 CC, reformados por Ley 11/1981, el testador, el contador-partidor expresamente autorizado por aquél, o el contador-partidor dativo designado por el Juez (art. 1057), pueden adjudicar todos o parte de los bienes hereditarios a alguno $o$ algunos de los hijos o descendientes, ordenando que éstos paguen en metálico la porción de los demás legitimarios. La facultad de pago en metálico no se extenderá a los legados de cosa específica y a las disposiciones particionales del testador señaladas en cosa determinada, que habrán de ser respetados en todo caso (arts. 845 y 846).

La decisión de pago en metálico de la legítima debe comunicarse a los restantes legitimarios en el plazo de un año desde la apertura de la sucesión -que coincide con el fallecimiento del causante- y debe hacerse en el plazo de otro año. El perceptor del metálico dispondrá de las garantías legales establecidas para el legatario de cantidad (arts. 48 y ss. LH); además, también podrá hacerse constar en el Registro de la Propiedad la adjudicación de un determinado inmueble a un hijo o descendiente con la obligación de satisfacer el pago en metálico, que será oponible frente a terceros adquirentes de dicho bien. Transcurrido el plazo sin que el pago haya tenido lugar, caducará la facultad de pagar en metálico y se repartirá la herencia según las disposiciones generales sobre la partición (art. 844), de tal manera que los legitimarios recuperarán su derecho a participar en los bienes hereditarios.

Para fijar la suma debida a los restantes legitimarios se atenderá al valor que tuvieren los bienes al tiempo de liquidarles la porción correspondiente, teniendo en cuenta los frutos o rentas hasta entonces producidos. Desde la liquidación hasta el momento del pago, el crédito en metálico devengará el interés legal (art. 847).
Conforme al art. 842, los adjudicatarios de los bienes podrán optar por satisfacer la legítima de los restantes herederos forzosos en bienes hereditarios, a pesar de estar autorizados a hacerlo en dinero. En cualquier caso será necesaria la conformidad de todos los legitimarios o la aprobación judicial para la partición que se lleve a cabo (art. 843).

Este régimen no aparece específicamente diseñado para resolver el problema de la continuidad en las empresas familiares, ya que su ámbito objetivo es más amplio; no obstante, éste será uno de los supuestos típicos en los que estará justificado el recurso a este mecanismo, especialmente cuando la explotación familiar sea el único bien importante existente en la herencia.

Sin embargo, el recurso a los arts. 841-847 no ha sido muy amplio en la práctica, fundamentalmente como consecuencia de dos factores: la necesidad de obtener la conformidad expresa de todos los herederos o la aprobación judicial para la eficacia de la partición así efectuada, y la brevedad del plazo previsto para realizar el pago en metálico. No obstante, esta vía (al igual que la del art. 829) puede resultar especialmente útil para mantener la unidad de determinados paquetes de acciones $o$ participaciones que no atribuyan control societario, lo que impediría acudir a la vía del art. 1056.2 CC, que posteriormente será examinada.

\section{La fiducia sucesoria a favor del cónyuge viudo y su incidencia sobre los derechos de los legitimarios}

En el CC el otorgamiento de testamento constituye un acto personalísimo del causante, ya que, como regla, no se admite la delegación de la facultad de testar (arts. 670, 830 y concordantes CC). En el ámbito de las empresas familiares, esta circunstancia dificulta la posibilidad de recurrir a un mecanismo que podría resultar muy útil para ordenar el proceso sucesorio de un manera eficaz, como es la delegación total o parcial a favor de un tercero de la facultad de designar sucesores y atribuirles bienes por diversos títulos. 
No obstante, la Ley 41/2003 modificó el art. 831 CC con objeto de facilitar la llamada "fiducia sucesoria" (que ya admitía anteriormente el mismo precepto, y que cuenta con precedentes en los territorios forales), por la cual el testador puede conferir a su cónyuge (o persona con la que tenga descendencia común) facultades amplísimas para distribuir los bienes de aquél, una vez fallecido, entre los hijos y descendientes comunes, pudiendo realizar atribuciones por cualquier título (institución de heredero, legado, mejora, etc.), aunque siempre con pleno respeto a las legítimas estrictas de éstos y a las disposiciones del propio causante.

En la práctica de la empresa familiar, el uso de la fiducia sucesoria puede resultar aconsejable, por ejemplo, cuando los hijos del titular sean menores de edad o carezcan de la necesaria experiencia al producirse el fallecimiento del causante, o en situaciones de incertidumbre respecto al futuro inmediato de la empresa, y más aún cuando ambos cónyuges hubieran estado vinculados a la actividad de la misma.

Por lo que ahora interesa, es importante insistir en que el fiduciario habrá de respetar en todo caso las legítimas estrictas de los descendientes comunes y las disposiciones del testador; pero, a tal efecto, podrá adjudicar, no sólo bienes privativos del fallecido, sino también los suyos propios, e incluso bienes pertenecientes a la sociedad de gananciales disuelta pero no liquidada. Al amparo de esta delegación, y como excepción al principio de la legítima entendida como "pars bonorum", se entiende que el fiduciario puede ordenar que las legítimas sean pagadas en metálico en los supuestos de los artículos 829 y 841-847. Se ha entendido incluso que también podrá hacer uso de la facultad que reconoce al testador el art. 1056.2 con objeto de mantener indivisa una explotación o el control sobre la misma, siempre que haya sido autorizado expresamente para ello por el comitente; si bien, considerando los límites que impone el art. 831, la adjudicación sólo podrá hacerse a favor de legitimarios, nunca de extraños.

\section{El artículo 1056.2 del CC como mecanismo específicamente orientado a facilitar el mantenimiento de la unidad de la explotación familiar de cara a la sucesión hereditaria}

Al hilo de la partición realizada por el propio testador, y de la expresa mención del respeto a las legítimas como único límite a la obligatoriedad de aquélla, el párrafo segundo del artículo $1056 \mathrm{CC}$ dispone:

El testador que en atención a la conservación de la empresa o en interés de su familia quiera preservar indivisa una explotación económica o bien mantener el control de una sociedad de capital o grupo de éstas podrá usar de la facultad concedida en este artículo, disponiendo que se pague en metálico su legítima a los demás interesados. A tal efecto, no será necesario que exista metálico suficiente en la herencia para el pago, siendo posible realizar el abono con efectivo extrahereditario $y$ establecer por el testador o por el contador-partidor por él designado aplazamiento, siempre que éste no supere cinco años a contar desde el fallecimiento del testador; podrá ser también de aplicación cualquier otro medio de extinción de las obligaciones. Si no se hubiere establecido la forma de pago, cualquier legitimario podrá exigir su legítima en bienes de la herencia. No será de aplicación a la partición así realizada lo dispuesto en el artículo 843 y en el párrafo primero del artículo 844.

La redacción actual procede de la reforma introducida por la Disp. Final $1^{a}$ de la Ley 7/2003, de 1 de abril, de la Sociedad Limitada Nueva Empresa, cuyo origen se sitúa en las recomendaciones formuladas en el "Informe de la Ponencia de Estudio para la problemática de la empresa familiar", elaborado por una Comisión especial del Senado en 2001 (cfr. Boletín Oficial de las Cortes Generales de 23 noviembre 2001). En su redacción original, el precepto disponía:

"El padre que en interés de su familia quiera conservar indivisa una explotación agrícola, industrial o fabril, podrá usar de la facultad 
concedida en este artículo, disponiendo que se satisfaga en metálico su legítima a los demás hijos".

Con esta previsión se trataba de facilitar al titular de una empresa la posibilidad de realizar la partición de su herencia de manera que se mantuviera aquélla indivisa, adjudicándola a alguno o algunos de sus legitimarios, y disponiendo que los demás recibieran su legítima en dinero. La norma, presente en la redacción originaria del $\mathrm{CC}$, suponía (junto a los ya mencionados arts. 821 y 829) una excepción al principio de intangibilidad cualitativa de la legítima, conforme al cual los legitimarios tienen derecho a exigir que se les pague aquélla con bienes de la herencia. En su origen era ésta una de las pocas disposiciones del CC reveladoras de una cierta preocupación legislativa por facilitar el mantenimiento de estructuras productivas -aproximándose así a los Derechos forales-, aun a costa de sacrificar principios básicos del sistema jurídico-privado; tendencia que a lo largo del siglo $\mathrm{XX}$ encontraría otras manifestaciones en el ámbito de la legislación especial agraria. No era -ni esel art. 1056.2, en cambio, una excepción a la regla de homogeneidad en la conformación de los lotes sancionada por el art. 1061 para la partición de la herencia, dado que este precepto nunca se ha considerado vinculante para el testador que realiza la partición, ni siquiera cuando ésta afecte a legitimarios.

La norma ya había visto relativizada su excepcionalidad, habida cuenta de la amplitud con que se admitió la posibilidad de pago de la legítima en metálico a raíz de la reforma de los arts. 841-847 operada en 1981. No obstante, ya por entonces se advirtió que los supuestos de hecho reconducibles al art. 1056.2 no quedaban sometidos al régimen general de pago de la legítima en metálico recogido por aquellos artículos, lo que obligaba a precisar las diferencias entre unos y otros supuestos, así como los posibles puntos de contacto, de cara a una posible aplicación analógica de las normas previstas para la hipótesis de los arts. 841-847 CC.

Partiendo de tales premisas, puede decirse que la incidencia de la reforma de 2003 sobre la situación preexistente se puede resumir en dos aspectos: por un lado, en la actualización del supuesto de hecho con arreglo a las modernas tendencias legislativas en materia de apoyo a la empresa familiar, especialmente a la hora de planificar la sucesión mortis causa; por otro, en el establecimiento de un régimen específico para el ejercicio de la facultad prevista en el precepto.

En cuanto al primer aspecto, el texto original del art. 1056.2 sólo contemplaba la hipótesis de titularidad individual del causante sobre la explotación; para salvar las dificultades que pudieran derivarse del posible carácter ganancial de la misma a efectos de mantener la unidad de la explotación en caso de disolución del régimen económico (por fallecimiento de uno de los cónyuges, divorcio, separación o cualquier otra causa) sólo se contaba con el insuficiente auxilio que pudiera derivarse de los arts. 1380 en cuanto a la eficacia de la disposición testamentaria sobre bienes gananciales concretos ("La disposición testamentaria de un bien ganancial producirá todos los efectos si fuere adjudicado a la herencia del testador. En caso contrario se entenderá legado el valor que tuviera al tiempo del fallecimiento"), y del art. 1406,2a, que reconocía a cada uno de los cónyuges, a efectos de liquidación de los gananciales, un derecho de adjudicación preferencial sobre "la explotación agrícola, comercial o industrial que hubiera llevado con su trabajo" (precepto éste último que también ha sido modificado por la Disp. Final $1^{\mathrm{a}}$ de la Ley $7 / 2003$, que ahora habla de "la explotación económica que gestione efectivamente"). La inadecuación de la norma a la realidad económica actual era manifiesta, dado que no tenía en cuenta la hipótesis -hoy en día más habitual- de utilización de formas societarias para articular la organización y transmisión de la empresa familiar, en atención a las importantes ventajas que ello ofrece, por ejemplo, en materia de responsabilidad, organización y fiscalidad. De ahí que la norma contemple ahora, no sólo el deseo de mantener la indivisión de la explotación de titularidad individual, sino también el de mantener el control sobre una sociedad de capital o sobre un grupo de éstas. Se trata de una importante 
novedad, que viene a resolver el problema planteado, por ejemplo, en la Sentencia del Tribunal Supremo -en adelante, STS- de 28 mayo 1958, acerca de la posibilidad de recurrir al art. 1056.2 para mantener indiviso un paquete de acciones con objeto de conservar el control de la sociedad dentro de la familia. En cambio, parece razonable entender que no podrá acudirse a este precepto con objeto de mantener el control de sociedades de mera tenencia de bienes, ya que ello permitiría eludir fácilmente todo el sistema legitimario.

En cuanto al segundo aspecto mencionado, la reforma de 2003 ha venido a dotar al supuesto del art. 1056.2 de un régimen legal del que hasta entonces prácticamente carecía, salvo en la medida en que se considerasen aplicables por analogía los arts. 841-847; al tiempo que introduce una referencia expresa a los arts. 843 y 844.1 para excluir su aplicación, lo que, sensu contrario, vendría a confirmar la posibilidad de tener en cuenta los criterios contenidos en los restantes preceptos que regulan, con carácter general, el pago de la legítima en metálico.

Respecto a los sujetos afectados, el nuevo texto opta por sustituir la referencia a los "hijos" por la más genérica de los "demás interesados". Con ello se confirma la idea, ya mantenida anteriormente, de que, al igual que los arts. 841847 permiten que se pague en metálico la legítima de hijos y descendientes, y pese a que el art. 1056.2 sólo se refería expresamente a los hijos, no existía razón alguna para no considerar incluidos en él también a los nietos del causante. Para algunos, la norma era aplicable, ya antes de la reforma, respecto a legitimarios no descendientes, e incluso -poniéndola en conexión con el art. 821- a extraños.

A la vista del texto reformado, se entiende que el testador puede adjudicar la explotación o el paquete de control, no sólo a alguno de sus herederos forzosos, sean o no descendientes, sino incluso a un extraño, aunque en tal caso cesará la posibilidad de acogerse a los beneficios fiscales establecidos para la sucesión en las empresas familiares. Por otra parte, no debe excluirse la posibilidad de que la adjudicación pueda hacerse a dos o más legitimarios, dejando a los demás dinero extrahereditario; en tal caso, cabe pensar que la finalidad de mantener la empresa justificará el que la disposición testamentaria mantenga su eficacia aun cuando sólo alguno de los adjudicatarios acepte la atribución.

En cuanto al sujeto activo, el art. 841 reconoce la posibilidad de optar por esta vía al testador, al contador-partidor expresamente autorizado por aquél, y al contador-partidor dativo al que se refiere el art. 1057; en el caso del art. 1056.2, parece que sólo el propio testador puede disponerlo al realizar personalmente la partición de sus bienes, bien en el testamento, bien por acto entre vivos complementario del mismo. No obstante, puede admitirse la atribución de dicha facultad al viudo, dentro de los límites del art. 831; como también que se encomiende a un contadorpartidor la ejecución de lo ordenado por el testador, más aún cuando el precepto incorpora ahora una referencia expresa a la posibilidad de que el aplazamiento para el pago pueda ser reconocido por el contador-partidor. Más dudoso parece que el encargo del testador a un tercero pueda incluir la posibilidad de optar entre la adjudicación conforme al art. 1056.2 ó la partición conforme a las reglas generales, o para designar a quienes habrán de recibir la adjudicación de los bienes o el pago en metálico de su legítima.

Por otra parte, la partición realizada por el testador conforme al art. 1056.2 será vinculante para todos los interesados, mientras que, según los arts. 841-847, los adjudicatarios de los bienes tienen la facultad de optar entre pagar a los demás legitimarios su cuota en metálico o exigir que se les pague con bienes de la herencia, previa partición de ésta conforme a las normas generales. En ambos casos, la partición realizada al amparo de los arts. 841-847 habrá de ser confirmada por todos los hijos o descendientes o, en su defecto, aprobada judicialmente, lo que no sucede en el supuesto del art. 1056.2, tal como se confirma ahora al excluirse expresamente la aplicabilidad al caso del art. 843 .

El pago de la legítima en metálico no aparece supeditada en los arts. 841-847 a la concurrencia de ninguna circunstancia especial 
en el patrimonio hereditario, sino sólo a la voluntad de los sujetos anteriormente indicados; en cambio, la excepcionalidad del art. 1056.2 obliga a considerar como presupuesto inexcusable para su aplicación la existencia de una explotación económica (empresarial o profesional) cuya división sólo pueda evitarse por esta vía, o de una situación de control societario (respecto a una sociedad individual o un grupo de éstas) que sólo pueda mantenerse del mismo modo; lo cual, a su vez, implica que no existan en la herencia dinero $u$ otros bienes con los que se pudiera pagar su legítima a los demás herederos forzosos, ya que, existiendo aquéllos, el testador no tendría que recurrir a este precepto para distribuir libremente sus bienes (art. 1056.1). En consecuencia, el dinero que habrá de satisfacerse a los legitimarios no adjudicatarios será, por hipótesis -y así lo reconoce expresamente la reforma-, dinero extrahereditario. Con todo, la mera previsión testamentaria bastará para dar por probada la existencia de la explotación o de la situación de control, correspondiendo la carga de la prueba sobre su inexistencia a quien impugne tal disposición (STS 19 mayo 1951).

Resulta irrelevante para la aplicación de este régimen cuál sea el título-propiedad, arrendamiento, etc.- que ostente el causante sobre la explotación, siempre que tenga la condición de privativo y no ganancial (STS 25 noviembre 1966), ya que, según ha afirmado la jurisprudencia, la partición hecha por el testador sólo puede ser eficaz y vinculante en cuanto recaiga sobre sus bienes privativos (entre otras muchas, STS 22 febrero 1997 y STS 7 septiembre 1998; vid., no obstante, art. 1380 CC). Por otra parte, si ya antes de 2003 parecía muy dudoso que pudiera ser revisado el criterio personal del causante en cuanto a la conveniencia de acudir a esta forma especial de partición "en interés de su familia", el mismo criterio habrá de seguirse en cuanto a la posibilidad de que el testador adopte su decisión "en atención a la conservación de la empresa", lo que, en todo caso, amplía notablemente el campo de las finalidades (no sólo familiares, sino también sociales, económicas, etc.) que la norma está llamada a cumplir. De ahí que actualmente sea razonable entender que el adjudicatario de la empresa ex art. 1056.2 puede ser un extraño, y no necesariamente uno de los legitimarios, lo que, eventualmente, puede constituir la vía más adecuada para garantizar la continuidad de la empresa, aun cuando ésta venga a quedar con ello fuera del control de la familia.

El uso por el testador de esta facultad habrá de presumirse válido mientras no se impugne con éxito en el juicio ordinario correspondiente por falta de algún requisito legal, no siendo adecuado para ello el marco del juicio divisorio (STS 17 octubre 1960); pero sí será exigible que el testador haya previsto expresamente que el pago de su legítima a los no adjudicatarios habrá de hacerse precisamente en metálico (o a través de "cualquier otro medio de extinción de las obligaciones", tal como dispone ahora el precepto, refiriéndose implícitamente a una posible compensación de créditos), sin que la voluntad de acogerse al art. 1056.2 pueda deducirse, por vía interpretativa, del mero hecho de que el testador haya adjudicado la empresa a algún legitimario sin que existan otros bienes o metálico en la herencia suficientes para satisfacer las restantes legítimas. Esta es la interpretación que, probablemente, debe hacerse de la oscura fórmula según la cual: "Si no se hubiere establecido la forma de pago, cualquier legitimario podrá exigir su legítima en bienes de la herencia”.

Para establecer el importe que ha de satisfacerse en metálico, habrá que aplicar las reglas generales sobre cómputo de las legítimas (art. 818). A estos efectos, es dudoso si la determinación del valor de los bienes que queden al morir el causante habrá de hacerse atendiendo al valor que tuvieran en ese momento, o bien al que tengan en el momento del cálculo de las legítimas, como resultaría de aplicar el criterio del art. 847, relativo al pago de las legítimas en metálico.

Sí parece claro que, por aplicación analógica del art. 847, una vez liquidado el valor en metálico que haya de satisfacerse, éste devengará el interés legal en favor de los no adjudicatarios. En tanto no se les satisfaga el importe íntegro de su legítima, éstos no tendrán la condición de simples acreedores respecto al 
adjudicatario, sino que su posición estará garantizada por la afección al pago de la totalidad del patrimonio hereditario; afección que será oponible incluso frente a terceros adquirentes de bienes hereditarios a través de su mención registral, y que, según alguna opinión, llevará implícita incluso la necesidad del consentimiento de aquéllos para la enajenación de los bienes. En caso de incumplimiento del adjudicatario, por tanto, los demás legitimarios podrán optar por ejercitar contra aquél las acciones derivadas de su condición de acreedores, o bien por utilizar los mecanismos generales de protección de la legítima, incluyendo la acción de partición de la herencia -previa revocación de la partición anterior-, que, en su caso, y cuando subsista el riesgo de que la explotación llegue a desmerecer mucho por su división (o de que la posición de control societario pueda desvanecerse), habrá de practicarse teniendo en cuenta el art. 1062: "Cuando una cosa sea indivisible o desmerezca mucho por su división, podrá adjudicarse a uno, a calidad de abonar a los otros el exceso en dinero. Pero bastará que uno solo de los herederos pida su venta en pública subasta, y con admisión de licitadores extraños, para que así se haga". Todo ello al margen de que el incumplimiento del adjudicatario pueda llevar consigo otras consecuencias, por voluntad expresa o implícita del causante, como la pérdida de lo recibido en concepto de mejora o con cargo al tercio de libre disposición, por aplicación del régimen de las disposiciones modales (art. 797).

Antes de 2003 se discutió si el adjudicatario podía contar con un plazo para realizar el pago de la cantidad debida. La reforma ha venido a incidir en esta importante cuestión, reconociendo la posibilidad de que el testador o el contador-partidor por él designado -sin necesidad de que éste último esté expresamente autorizado para ello, a diferencia de lo previsto en el art. 841-, puedan conceder un aplazamiento de pago por un tiempo máximo de cinco años desde el fallecimiento del testador, lo que puede suponer una importante ventaja financiera para garantizar la subsistencia de la empresa y evitar su descapitalización. Anteriormente no parecía posible que ni siquiera el propio causante pudiera autorizar un aplazamiento sobre la base del art. 1056.2, ya que ello hubiera supuesto admitir una nueva excepción al principio de intangibilidad cualitativa de la legítima (art. 813), carente, en este caso, de apoyo legal. En defecto de previsión expresa, el adjudicatario no podrá beneficiarse de aplazamiento alguno $\mathrm{y}$, por tanto, los demás podrán exigir el pago inmediato (art. 1113). Es claro que habría sido oportuno reconocerle un término prudencial para cumplir, excluyendo la posibilidad de que los demás legitimarios pudieran promover mientras tanto la división judicial de la herencia; recuérdese, en este sentido, que la jurisprudencia ha negado a los legitimarios la posibilidad de recurrir al juicio de división de la herencia cuando la partición haya sido realizada por el propio testador (SSTS 3 diciembre 1931, 17 octubre 1960 y 28 junio 1961; vid. también art. 782.1 de la Ley de Enjuiciamiento Civil de 2000).

Una solución razonable hubiera consistido en aplicar analógicamente el plazo de un año desde que los interesados hubieran conocido la disposición del testador, conforme al art. 844.1, aunque esta solución se ve dificultada ahora por la expresa exclusión de la posibilidad de aplicar dicho precepto.

En consecuencia, cabe pensar que el término de cumplimiento habrá de fijarse judicialmente siguiendo el criterio general del art. 1128.1; transcurrido dicho plazo sin que se haya producido el pago, podrá considerarse "caducada" la facultad conferida por el art. $1056.2 \mathrm{y}$, en consecuencia, los legitimarios podrán exigir que se les pague su legítima en bienes de la herencia, procediéndose a repartir la herencia según las normas generales (art. 844.2, cuya aplicación analógica sí permite el art. 1056.2). Todo ello sin perjuicio de que, eventualmente, los colegitimarios puedan optar por exigir el cumplimiento forzoso de la obligación de pago en metálico, conforme al régimen general de las disposiciones modales.

Los que reciban su legítima en dinero tendrán la consideración de legatarios o sucesores a título singular, por lo que no responderán, en principio, de las deudas hereditarias. Para la 
inscripción registral de los inmuebles adjudicados por esta vía, cabría aplicar analógicamente el art. 80.2.a) del Reglamento Hipotecario, relativo a las adjudicaciones realizadas conforme a los arts. 841-847; de manera que el adjudicatario podrá inscribir los bienes a su nombre en virtud del testamento, acompañado de la escritura de adjudicación, expresando que ésta se verifica al amparo del art. 1056.2, y, por aplicación del art. 15.1 LH, practicando la mención del derecho de los demás legitimarios. No será necesario, en cambio, acompañar los documentos que acrediten la aceptación del adjudicatario, la confirmación de los demás legitimarios o la aprobación judicial, por no ser estos requisitos exigibles conforme al art. 1056.2. El pago de la cantidad debida a los no adjudicatarios se hará constar en el Registro por nota marginal mediante el correspondiente documento público acreditativo.

\section{Conclusión}

Si bien es cierto que el sistema legitimario del Código Civil español, debido a su amplitud y rigidez (especialmente en lo que se refiere al derecho de los herederos forzosos a recibir su porción legitimaria precisamente en bienes de la herencia), plantea algunas dificultades importantes a la hora de planificar la sucesión hereditaria en el ámbito de las empresas familiares, existen diferentes mecanismos -cada uno de ellos sometido a presupuestos y requisitos específicos- que pueden ser utilizados por el testador para evitar que tales circunstancias puedan poner en peligro la continuidad de la empresa a su muerte. En particular, el recurso al pago de las legítimas en dinero extrahereditario, o incluso mediante la entrega de bienes ajenos a la herencia, puede ser un instrumento idóneo para evitar resultados indeseables, como la división de la empresa, la pérdida del control de la misma, o la necesidad de proceder a la venta de activos. En todo caso, para la adecuada utilización de tales instrumentos siempre será conveniente que el empresario afronte la planificación de su propia sucesión con la necesaria antelación y el debido asesoramiento, atendiendo a las circunstancias particulares de la empresa y de la familia.

\section{Bibliografía}

Albaladejo García, M. y Díaz Alabart, S. (1986). En Albaladejo, M. (dir.), Comentarios al Código Civil y Compilaciones forales. t. XIV, vol. $2^{\circ}$. Madrid: Editoriales de Derecho Reunidas SA.

De la Cámara, M. (1991). Comentario a los arts. 1051 a 1087. En Comentario del Código Civil, t. I (p. 2466). Madrid: Ministerio de Justicia.

Espejo Lerdo de Tejada, M. (2006). La reforma del Código civil por la Ley de Sociedad Limitada Nueva Empresa. En Abril Campoy, J. M., y Amat Llarí, M. E. (coord.), Homenaje al Profesor Lluis Puig I Ferriol, vol. I (pp. 12491270). Valencia: Ed. Tirant lo Blanch.

Fernández-Tresguerres García, A. (2004). La Ley 7/2003, de 1 de abril, de la Sociedad Limitada Nueva Empresa por la que se modifica la Ley 2/1995, de 23 de marzo, de Sociedades de Responsabilidad Limitada. La Ley. Revista jurídica española de doctrina, jurisprudencia y bibliografía, 1, 2004, 1666-1690.

Garrido de Palma, V. M. (2004). Los nuevos artículos 831 y $1056.2^{\circ}$ del Código Civil. Algunas aplicaciones. En González Porras, J.M. y Méndez González, F.P., Libro Homenaje al Profesor Manuel Albaladejo García, t. I (pp. 2021-2029). Murcia: Universidad de Murcia, Secretariado de Publicaciones e Intercambio Científico.

Huerta Trólez, A. (2004). La empresa familiar ante el fenómeno sucesorio. Revista Jurídica del Notariado, 50, 93-138.

Lacruz Berdejo, J. L. y Sancho Rebullida, F. (1993). Elementos de Derecho Civil, V. Derecho de Sucesiones ( $5^{\mathrm{a}}$ ed.). Barcelona: Ed. Bosch.

López Frías, M.J. (2007). La delegación de la facultad de mejorar del artículo 831 del Código Civil. En Sánchez Calero, F. J. y García Pérez, R. (coords.), Protección del patrimonio familiar (pp. 39-73). Valencia: Ed. Tirant lo Blanch. 
Palazón Garrido, M. L. (2007). La conservación de la empresa familiar a través de la facultad contemplada por el nuevo artículo 1056, párrafo segundo del Código Civil. En Sánchez Calero F. J. y García Pérez R. (coords.), Protección del patrimonio familiar (pp. 309-345). Valencia: Ed. Tirant lo Blanch.

Reverte Navarro, A. (2004). Sucesión 'mortis causa' en la empresa y sucesión legitimaria (Notas al nuevo art. 1.056, II del Código Civil). Murcia: Real Academia de Legislación y Jurisprudencia de Murcia.

Roca Guillamón, J. (2004). Delegación fiduciaria de la facultad de distribuir y mejorar (Notas al artículo 831 del Código Civil - Ley 41/2003). En González Porras, J.M. y Méndez González, F.P., Libro Homenaje al Profesor Manuel Albaladejo García, t. II (pp. 42794301). Murcia: Universidad de Murcia, Secretariado de Publicaciones e Intercambio Científico.

Roca Sastre Muncunill, L. (2000). Derecho de sucesiones, IV. Barcelona: Ed. Bosch.
Rueda Esteban, L. (2005). La fiducia sucesoria del artículo 831 del Código Civil. En Garrido Melero, M. y Fugardo Estivill, J. M. (coords.), El patrimonio familiar, profesional $y$ empresarial. Sus protocolos, IV (pp. 155-204). Barcelona: Editorial Bosch.

Rueda Esteban, L. (2005). La modificación del párrafo segundo del artículo 1056 del Código Civil. En Garrido Melero, M. y Fugardo Estivill, J. M. (coords.), El patrimonio familiar, profesional y empresarial. Sus protocolos, IV (pp. 205-238). Barcelona: Editorial Bosch.

Sierra Pérez, M. (2007). La fiducia sucesoria en Derecho común: El artículo 831 del Código Civil en la Ley 41/2003, de 18 de noviembre. Revista Aranzadi de Derecho Patrimonial, 19, 89-124.

Vallet de Goytisolo, J. (1986). En Albaladejo, M. (dir.), Comentarios al Código Civil y Compilaciones forales, $\mathrm{t}$. XIV, vol. $2^{\circ}$. Madrid: Editoriales de Derecho Reunidas SA.

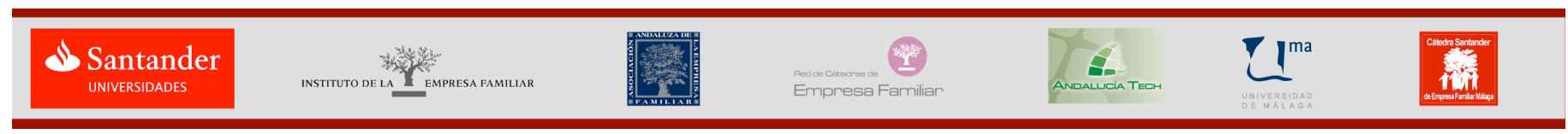

